\title{
Penetration Force And Cannula Sliding Profiles Of Different Pen Needles: The PICASSO Study [Erratum]
}

Leonardi L, Viganò M, Nicolucci A. Med Devices (Auckl). 2019;12:311-317.

The authors of this article have advised that during the typesetting process of this manuscript the wrong image

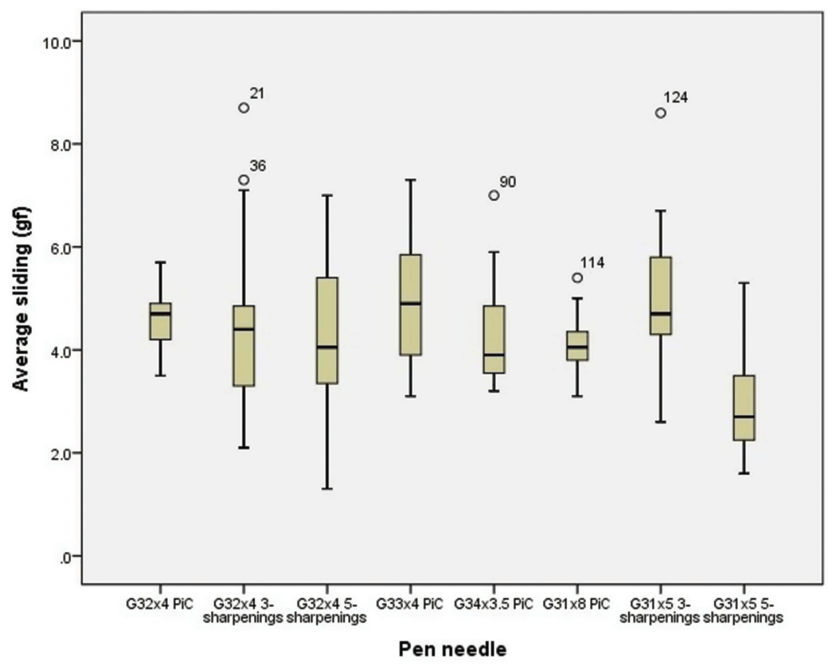

Medical Devices: Evidence and Research

Publish your work in this journal

Medical Devices: Evidence and Research is an international, peerreviewed, open access journal that focuses on the evidence, technology, research, and expert opinion supporting the use and application of medical devices in the diagnosis, monitoring, treatment and management of clinical conditions and physiological processes. The identification of novel devices and optimal use of existing devices was used for Figure 4. The authors did not realize this error until after the paper was published. The correct image for Figure 4 is as follows: 